\title{
Research on the Causes and Responsive Measures of China's Fiscal Expenditure Solidification
}

\author{
Li Yan*, Peng Chao \\ Email address: \\ liyancufe@126.com (Li Yan),pcslz@163.com (Peng Chao) \\ ${ }^{*}$ Corresponding author
}

School of Public Finance and Tax, Central University of Finance and Economics, Beijing, China

To cite this article:

Li Yan, Peng Chao. Research on the Causes and Responsive Measures of China's Fiscal Expenditure Solidification. Journal of World Economic Research. Vol. 7, No. 2, 2018, pp. 82-91. doi: 10.11648/j.jwer.20180702.15

Received: August 4, 2018; Accepted: August 23, 2018; Published: September 28, 2018

\begin{abstract}
The budget enforcement, as an important indicator for measuring the collection and use of fiscal funds, plays an essential role in the promotion of Chinese reform. However, in recent years, Chinese fiscal expenditure has shown the tendency of solidification, which slows budget implementation progress, makes a large amount of financial funds can't be efficiently paid, and sharpens the contradiction between the coexistence of "shortage" and "precipitation" of funds. That is to say, in the practice of China's budgetary expenditure, the expenditure solidification directly constrains the implementation effect of budget expenditure, making the expenditure cannot be effectively paid. Therefore, this paper starts from the existing problems in the fiscal expenditure, systematically analyzes the historical basis and current situation of China's fiscal expenditure solidification. Through the analysis, it can be found the recent fiscal expenditure shows the convergence trend. That is to say in the context of increasing economic pressure, China's fiscal expenditure show a uptrend situation, instead of decreasing in response to the declined fiscal revenue. Moreover, in China, no matter in central government or local governments, the scale and structure of education, medical, health care and other expenses have shown the convergence trend. The phenomenon is called China's fiscal expenditure solidification, and the reason for this phenomenon include the inertia of legally mandated expenditure, the flaws in transfer payments system, the unscientific and unstandardized budget management process, and the contradiction between policy and system arrangement and practice. And in order to solve the problem, it should be started from the top-level design, completing the relevant measures and strengthening modern budget management.
\end{abstract}

Keywords: Expenditure, Solidification, Budget

\section{Introduction}

In 2009, the news with the title of "China's financial sector will spend \$2 trillion in a short period at the end of the year" discloses the relevant problems of Chinese budget expenditure. In response, the Ministry of Finance of the People's Republic of China immediately stated that they would firmly strengthen the management of fiscal expenditure, and prevent a large number of money being spent in a short period as the end of the year. Besides, in 2010, the policy of "Guidance on further budget implementation" [1] was published, which required to enhance the timeliness and balance of budget enforcement. And in 2014, the policy of "Notification of measures to assess the progress of local budgetary expenditures" [2] was issued, which meant the gradual construction of the assessment system of budget expenditure progress and, at a certain degree, improved the budget expenditure effect. But afterwards, the conflict between the tax and administration fee reduction in China and the income reduction and expenditure rigidity remained prominent.

In order to further strengthen the budget enforcement management and expedite the expenditure progress, in 2018, the Ministry of Finance published "Notice on strengthening the management of local budget implementation and accelerating the progress of expenditure" [3], which specified the requirements for transfer payment, budget implementation, storage funds and so on. It can be found that the budget enforcement, serving as an important indicator for measuring 
the collection and use of fiscal funds, directly affect China's reform progress and the arbitrariness or inefficiency in its implementation will weaken the legitimacy and effectiveness of the government enforcement. [4] Furthermore, with expenditure and policy becoming the priority of budgetary scrutiny, the implementation of budget expenditure also becomes an integral part of budgetary enforcement.

However, in the practice of China's budgetary expenditure, the expenditure solidification directly constrains the implementation effect of budget expenditure, making the expenditure cannot be effectively paid. The fiscal expenditure solidification refers to the characteristics in some expenditure items on the demands and use of funds, like only increasing without decrease and lack of overall planning space, and as a result, some regions, departments and expenditure projects are financially constrained, while the budgetary arrangement in other areas, departments and expenditure projects is difficult to implement. [5-6] The reasons behind this can be classified into three aspects, the root reason, system reason and technological reason. [7] And to alleviate the current fiscal revenue and expenditure contradiction lie in the acceleration needs to accelerate the expenditure progress and break the expenditure solidification and uplift the capital usage efficiency. [8] Thus, this paper starts from the current situation and problems in China's fiscal expenditure, systematically analyzes the historical basis and situation of financial solidification and tries to help relieve the income and expenditure contradiction through the "expenditure side" of budget.

\section{Current Situation and Problems of Fiscal Expenditure}

Judging from the table of China's fiscal expenditure (Table 1), the fiscal expenditure has shown the tendency of expansion no matter in Central government or in local governments. And the central government fiscal expenditure has fallen from $23 \%$ in 2007 to a stable level of $15 \%$, and the local government expenditure gradually increases from $77 \%$ in 2007 to the stable level of around $85 \%$. So it can be said that against the background of a changed public expenditures and considering Tax Rebates and Transfer Payments factors, the ratio of central government expenditure to local expenditure remains stable at $3: 17$.

Table 1. Fiscal expenditure and its proportion.

\begin{tabular}{|c|c|c|c|c|c|}
\hline & $\begin{array}{l}\text { National fiscal } \\
\text { expenditure }\end{array}$ & $\begin{array}{l}\text { Central government } \\
\text { expenditure }\end{array}$ & $\begin{array}{l}\text { Local fiscal } \\
\text { expenditure }\end{array}$ & $\begin{array}{l}\text { Proportion of central government } \\
\text { expenditures }(\%)\end{array}$ & $\begin{array}{l}\text { Proportion of local fiscal } \\
\text { expenditure }(\%)\end{array}$ \\
\hline 2007 & 49781.35 & 11442.06 & 38339.29 & 23.0 & 77.0 \\
\hline 2008 & 62592.66 & 13344.17 & 49248.49 & 21.3 & 78.7 \\
\hline 2009 & 76299.93 & 15255.79 & 61044.14 & 20.0 & 80.0 \\
\hline 2010 & 89874.16 & 15989.73 & 73884.43 & 17.8 & 82.2 \\
\hline 2011 & 109247.79 & 16514.11 & 92733.68 & 15.1 & 84.9 \\
\hline 2012 & 125952.97 & 18764.63 & 107188.34 & 14.9 & 85.1 \\
\hline 2013 & 140212.1 & 20471.76 & 119740.34 & 14.6 & 85.4 \\
\hline 2014 & 151785.56 & 22570.07 & 129215.49 & 14.9 & 85.1 \\
\hline 2015 & 175877.77 & 25542.15 & 150335.62 & 14.5 & 85.5 \\
\hline 2016 & 187755.21 & 27403.85 & 160351.36 & 14.6 & 85.4 \\
\hline
\end{tabular}

Unit: 100 million

Data source: National Bureau of Statistics, http://data.stats.gov.cn/.

\subsection{Key project Expenditure}

Through analyzing the specific items of national fiscal expenditure (Table 2), when the overall expenditure scale is expanding, the proportion of the education expenditure scale has reached the highest point of $16.98 \%$, and the next one is the social security and employment and expenditure, $12.10 \%$. In the central fiscal expenditure (Table 3), except for the defense expenditure, scientific technology, general common services and education expenditures are in a relatively high level; And for the local fiscal expending projects (Table 4), expenditures, like education, social security and employment, agriculture, forestry and water affairs and general common services expenditures are relatively high.

From the above analysis, firstly, no matter in the central government expenditure or in the local government expenditure, the general services expenditures that make sure the normal operation of government institutions take up a relatively high proportion; Secondly, although specific provision has been made to cancel the legally mandated expenditure mechanism, from the perspective of expenditure structure, education, science, health care and other key projects expenditure is obviously higher than other project expenditure. In each province (Table 5), the variation coefficient 1 of the proportion of the legally mandated expenditure items to the fiscal expenditure is similar and is relatively small, which means these expenditure has the trend of convergence growth and a smaller amount of variation and it doesn't vary from place to place because of different needs.

There are two reasons for this phenomenon. Firstly, the cancellation of legally mandated expenditure mechanism hasn't been well implemented and there is institutional inertia. Second, the expenditures in education, science, agriculture, etc., in recent years, have become the key expenditures items

\footnotetext{
1 The variable coefficient is a statistical magnitude to measure each observation value, and its computational formula is variable coefficient = standard deviation / average value, which can directly reflect the fluctuation of each expenditure item.
} 
about people's livelihood that needs especially protected.

Table 2. The scale of each item in the national fiscal expenditure.

\begin{tabular}{lll}
\hline & $\begin{array}{l}\text { The annual average of } \\
\text { expenditures (100 million RMB) }\end{array}$ & Annual average proportion (\%) \\
\hline General public service expenditure & 11586.07 & 9.91 \\
Foreign expenditure & 329.92 & 0.28 \\
Aid to foreign countries & 133.06 & 0.11 \\
Defense expenditure & 6529.18 & 5.58 \\
Public security expenditure & 6777.95 & 5.80 \\
Armed police expenditure & 826.29 & 0.71 \\
Education expenditure & 17624.76 & 15.07 \\
Science and technology expenditure & 4332.62 & 3.71 \\
Culture, sports and media expenditure & 2056.75 & 1.76 \\
Social security and employment expenditure & 12375.33 & 10.58 \\
Expenditures for medical care and public health & 7078.86 & 6.05 \\
Environmental protection expenditure & 2921.61 & 2.50 \\
Expenditure on urban and rural community affairs & 9365.16 & 8.01 \\
Expenditure on agricultural, forestry and water affairs & 10820.13 & 9.25 \\
Transportation expenditure & 7270.36 & 6.22 \\
Vehicle purchase tax expenditure & 1358.67 & 1.16 \\
Expenditure for post-earthquake recovery and reconstruction & 571.06 & 0.49 \\
Other Expenditure & 2928.58 & 2.50 \\
\hline
\end{tabular}

Data source: National Bureau of Statistics, http://data.stats.gov.cn/.

Table 3. The scale of items in central government expenditure.

\begin{tabular}{lll}
\hline & $\begin{array}{l}\text { The annual average of } \\
\text { expenditures (100 million RMB) }\end{array}$ & Annual average proportion (\%) \\
\hline General public service expenditure & 1264.40 & 6.75 \\
Foreign expenditure & 328.09 & 1.75 \\
Aid to foreign countries & 133.04 & 0.71 \\
Defense expenditure & 6354.06 & 33.92 \\
Public security expenditure & 1129.88 & 6.03 \\
Armed police expenditure & 626.48 & 3.34 \\
Education expenditure & 944.21 & 5.04 \\
Science and technology expenditure & 1921.98 & 10.26 \\
Culture, sports and media expenditure & 190.24 & 1.02 \\
Social security and employment expenditure & 563.41 & 3.01 \\
Expenditures for medical care and public health & 70.63 & 0.38 \\
Environmental protection expenditure & 148.69 & 0.79 \\
Expenditure on urban and rural community affairs & 13.12 & 0.07 \\
Expenditure on agricultural, forestry and water affairs & 483.22 & 2.58 \\
Transportation expenditure & 856.82 & 4.57 \\
Vehicle purchase tax expenditure & 615.81 & 3.29 \\
Expenditure for post-earthquake recovery and reconstruction & 76.99 & 0.41 \\
Other Expenditure & 303.21 & 1.62 \\
\hline
\end{tabular}

Data source: National Bureau of Statistics, http://data.stats.gov.cn/.

Table 4. The scale of item in local governments expenditure.

\begin{tabular}{lll}
\hline & $\begin{array}{l}\text { The annual average of } \\
\text { expenditures (100 million RMB) }\end{array}$ & Annual average proportion (\%) \\
\hline General public service expenditure & 10321.67 & 10.51 \\
Foreign expenditure & 1.83 & 0.002 \\
Defense expenditure & 175.12 & 0.18 \\
Public security expenditure & 5648.07 & 5.75 \\
Education expenditure & 16680.55 & 16.98 \\
Science and technology expenditure & 2179.31 & 2.22 \\
Culture, sports and media expenditure & 1866.51 & 1.90 \\
Social security and employment expenditure & 11881.86 & 12.10 \\
Expenditures for medical care and public health & 7008.24 & 7.14 \\
Energy conservation and protection expenditure & 2772.92 & 2.82 \\
Expenditure on urban and rural community affairs & 9352.04 & 9.52 \\
Expenditure on agricultural, forestry and water affairs & 10336.92 & 10.53 \\
Transportation expenditure & 6413.54 & 6.53 \\
Expenditures for resource exploration, power information, etc. & 4132.30 & 4.21 \\
\hline
\end{tabular}




\begin{tabular}{lll}
\hline & $\begin{array}{l}\text { The annual average of } \\
\text { expenditures (100 million RMB) }\end{array}$ & Annual average proportion (\%) \\
\hline Business services and other business expenditure & 1441.30 & 1.47 \\
Expenditure on financial regulation, etc. & 285.66 & 0.29 \\
Expenditure for post-earthquake recovery and reconstruction & 532.57 & 0.54 \\
Expenditures for land, resources and meteorology & 1487.64 & 1.51 \\
Housing security expenditure & 4285.67 & 4.36 \\
Expenditure on grain and oil material reserve management and other affairs & 826.54 & 0.84 \\
National debt servicing expenses & 718.93 & 0.73 \\
Other expenses & 2625.50 & 2.67 \\
\hline
\end{tabular}

Data source: National Bureau of Statistics, http://data.stats.gov.cn/.

Table 5. The variable coefficient of proportion of legally mandated projects from 2007 to 2016.

\begin{tabular}{|c|c|c|c|c|c|c|}
\hline & $\begin{array}{l}\text { Educa } \\
\text { tion }\end{array}$ & $\begin{array}{l}\text { Science and } \\
\text { technology }\end{array}$ & $\begin{array}{l}\text { Culture, sports } \\
\text { and media }\end{array}$ & $\begin{array}{l}\text { Social security and } \\
\text { employment }\end{array}$ & $\begin{array}{l}\text { Health care and family } \\
\text { planning }\end{array}$ & $\begin{array}{l}\text { Agriculture, forestry and } \\
\text { water affairs }\end{array}$ \\
\hline Beijing & 0.1 & 0.1 & 0.1 & 0.1 & 0.1 & 0.1 \\
\hline Tianjin & 0.1 & 0.1 & 0.1 & 0.1 & 0.1 & 0.1 \\
\hline Hebei & 0.0 & 0.1 & 0.1 & 0.1 & 0.2 & 0.2 \\
\hline Shanxi & 0.1 & 0.3 & 0.1 & 0.1 & 0.2 & 0.1 \\
\hline Inner Mongolia & 0.1 & 0.1 & 0.1 & 0.0 & 0.1 & 0.1 \\
\hline Liaoning & 0.1 & 0.2 & 0.2 & 0.2 & 0.2 & 0.1 \\
\hline Jilin & 0.1 & 0.1 & 0.1 & 0.1 & 0.2 & 0.2 \\
\hline Heilongjiang & 0.1 & 0.1 & 0.1 & 0.1 & 0.1 & 0.2 \\
\hline Shanghai & 0.1 & 0.2 & 0.1 & 0.1 & 0.1 & 0.2 \\
\hline Jiangsu & 0.0 & 0.1 & 0.1 & 0.1 & 0.2 & 0.2 \\
\hline Zhejiang & 0.0 & 0.0 & 0.1 & 0.2 & 0.1 & 0.1 \\
\hline Anhui & 0.1 & 0.4 & 0.1 & 0.1 & 0.2 & 0.1 \\
\hline Fujian & 0.1 & 0.1 & 0.1 & 0.1 & 0.1 & 0.1 \\
\hline Jiangxi & 0.1 & 0.3 & 0.1 & 0.1 & 0.1 & 0.0 \\
\hline Shandong & 0.1 & 0.1 & 0.1 & 0.0 & 0.2 & 0.1 \\
\hline Henan & 0.1 & 0.1 & 0.1 & 0.1 & 0.2 & 0.1 \\
\hline Hubei & 0.1 & 0.4 & 0.1 & 0.1 & 0.2 & 0.1 \\
\hline Hunan & 0.1 & 0.1 & 0.2 & 0.1 & 0.2 & 0.1 \\
\hline Guangdong & 0.1 & 0.2 & 0.3 & 0.1 & 0.2 & 0.1 \\
\hline Guangxi & 0.0 & 0.2 & 0.2 & 0.1 & 0.2 & 0.1 \\
\hline Hainan & 0.0 & 0.1 & 0.1 & 0.1 & 0.2 & 0.1 \\
\hline Chongqing & 0.1 & 0.1 & 0.1 & 0.1 & 0.2 & 0.1 \\
\hline Sichuan & 0.1 & 0.2 & 0.2 & 0.1 & 0.2 & 0.1 \\
\hline Guizhou & 0.1 & 0.2 & 0.1 & 0.1 & 0.1 & 0.1 \\
\hline Yunnan & 0.1 & 0.1 & 0.1 & 0.1 & 0.1 & 0.1 \\
\hline Xizang & 0.1 & 0.3 & 0.1 & 0.3 & 0.2 & 0.1 \\
\hline Shanxi & 0.1 & 0.1 & 0.1 & 0.1 & 0.2 & 0.3 \\
\hline Gansu & 0.1 & 0.1 & 0.1 & 0.0 & 0.1 & 0.1 \\
\hline Qinghai & 0.1 & 0.3 & 0.2 & 0.3 & 0.1 & 0.1 \\
\hline Ningxia & 0.2 & 0.2 & 0.2 & 0.2 & 0.1 & 0.1 \\
\hline Xinjiang & 0.1 & 0.3 & 0.1 & 0.3 & 0.2 & 0.1 \\
\hline
\end{tabular}

Date source: It is computed through the each fiscal expenditure items in the final report in each province from 2007 to 2016.

\subsection{Transfer Payments}

In terms of overall scale (Figure 1), compared with 2007, both the general transfer payments and the special transfer payments have increased. With regard to the increase rate (Figure 1), the general transfer payments rate reached the highest point in 2011, approximately $38 \%$, and then decrease and got to the lowest point in 2015, 3.2\%. But it increased to $12 \%$ in 2016 . Though the special transfer payments hit the maximum in 2015 at $14.2 \%$, but in accordance with the policy requirement, it declines gradually from $44.4 \%$ in 2008 to $-4.2 \%$ in 2016. From the view of structural proportions, when both the scale and increase rate are different, the general transfer payments and the special transfer payments are stable, and the proportion of the general transfer payments in the central fiscal expenditure has increased, but the proportion of the special transfer payments gradually declined (Figure 3). Besides, the relative proportion of the general transfer payments and the special transfer payments is around 6:4 (Figure 4). 


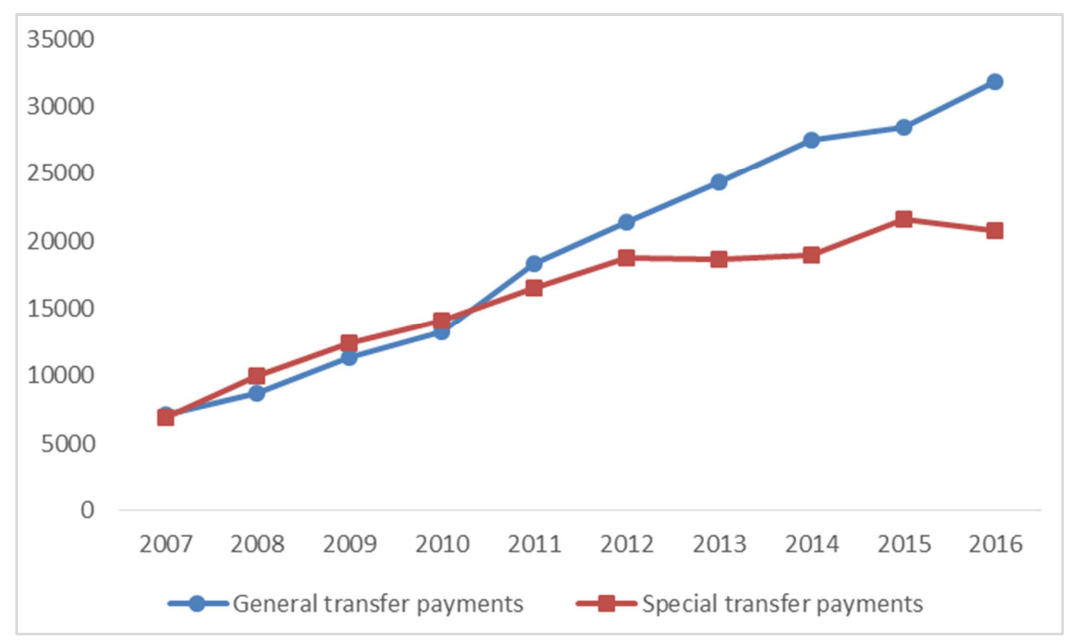

Data source: The budget department in the Ministry of Finance of the People's Republic of China, http://yss.mof.gov.cn/zhengwuxinxi/caizhengshuju/.

Figure 1. Transfer payment in general public budget from central government to local governments (100 million RMB).

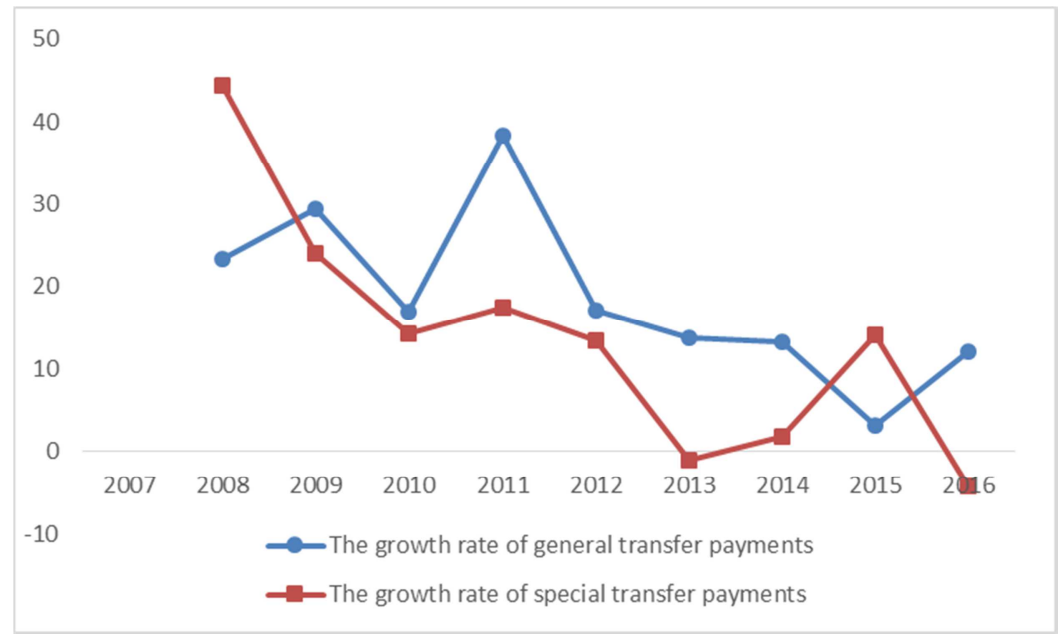

Data source: The budget department in the Ministry of Finance of the People's Republic of China, http://yss.mof.gov.cn/zhengwuxinxi/caizhengshuju/.

Figure 2. The growth rate of transfer payments from central government to local governments (\%).

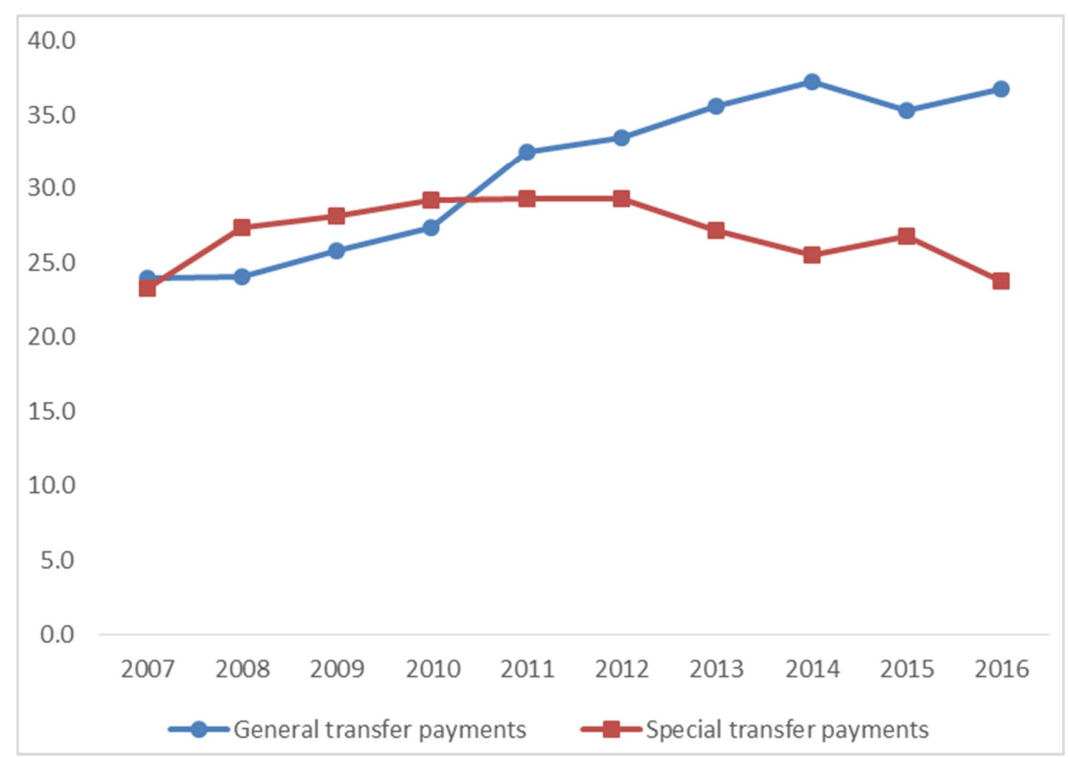

Data source: The budget department in the Ministry of Finance of the People's Republic of China, http://yss.mof.gov.cn/zhengwuxinxi/caizhengshuju/.

Figure 3. Transfer payments account for the proportion of central government expenditures. 


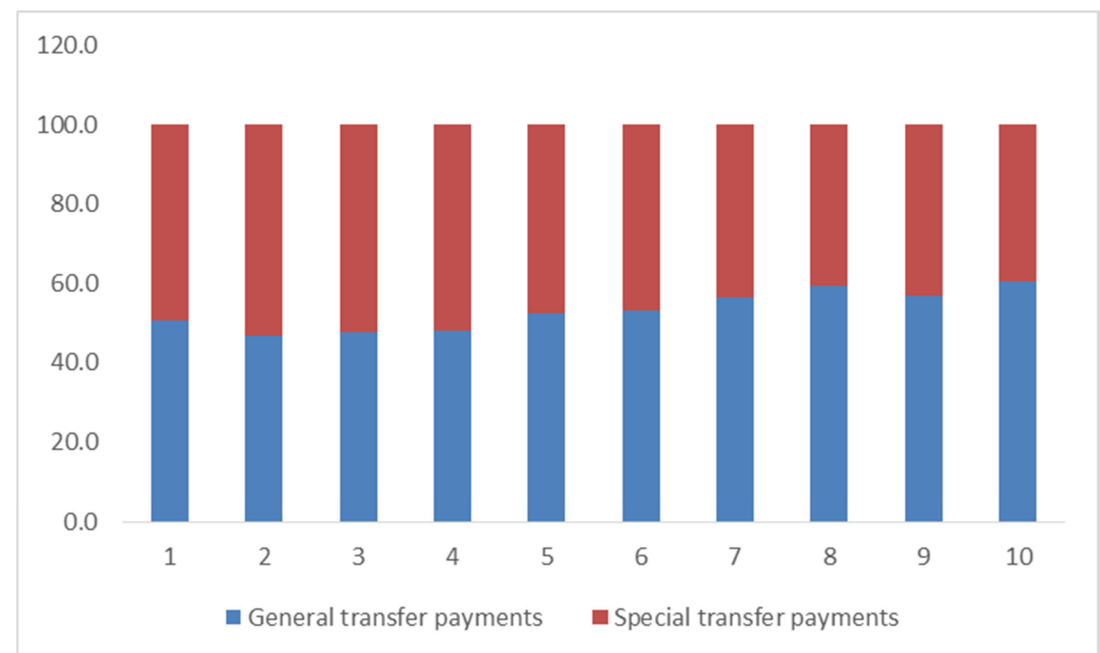

Data source: The budget department in the Ministry of Finance of the People's Republic of China, http://yss.mof.gov.cn/zhengwuxinxi/caizhengshuju/.

Figure 4. Transfer payments account for the relative proportion.

Through the above analysis, it can be found the recent fiscal expenditure shows the following convergence trend:

Firstly, in the context of increasing economic pressure, China's fiscal expenditure show a uptrend situation, instead of decreasing in response to the declined fiscal revenue.

Second, in China, no matter in central government or local governments, the scale and structure of education, medical, health care and other expenses have shown the convergence trend.

\section{Analysis on the Causes for the Solidification of Fiscal Expenditure}

\subsection{The Inertia of Legally Mandated Expenditure Restrains the Use Flexibility of Funds}

As for the legally mandated expenditure, it can be literally translated into the fiscal expenditure formed through "preferential" budget arrangement in specific region (project) according to related laws and regulations. Before 2013, the central government stipulated that the budgetary arrangement of agriculture, education, science, medical treatment and public health, social security, culture and family planning shall be higher than the financial growth of that year, and thus the legally mandated expenditure is formed. In the specific development background, it played an indelible role in ensuring the development of relevant fields. However, with the progress of China's reform, these legally mandated expenditure has no consideration for differences, it solidifies local expenditure, further increases the financial stock and enhances the difficulty of government pooling funds.

Specifically speaking, at first, even the legally mandated expenditure are suitable for the original purpose, but its suitability will be largely reduced with the rapid change of the development, and the cumulative effect will lead to a huge deviation between supply and demand. Next, for any expenditure item, its importance should be based on equity and competition, but the compulsory growth requirement in the legally mandated expenditure notably goes against this rule.

Therefore, in the resolution of the third plenary session of the 18th CPC central committee, it has been specified that governments should clean up and standardize the arrangements for key expenditures related to the growth in fiscal revenue or to GDP, and they required all expenditure items shall not compulsorily related to fiscal revenue or GDP. Currently, from the expenditure in agriculture, education, science, medical treatment and public health and so on, although some compulsory policies has been invalid, in some areas, there still remained the legal basis for the legally mandated expenditure arrangement in accordance with the old laws and regulation. And even after the resolution of the third plenary session of the 18 th CPC central committee, the revised law still makes requirement for its growth rate implementation, such as in the Education Law. The legally mandated expenditure makes the fiscal expenditure increase as a fixed way, and reduces the flexibility of the funds.

\subsection{The Flaws in Transfer Payments System Strengthen the Solidification of Expenditure}

\subsubsection{General Transfer Payments}

In theory, general transfer payments refers to a kind of payment method that the superior government doesn't have specific requirement for the lower level government. In practice, among other general transfer payments, except for balanced transfer payment, system of subsidies and settlement payment and other a few projects, other projects have specific purposes. In accordance with the "The state council's audit report on the implementation of the central budget and other fiscal revenues and expenditures in 2017", in transfer payments of the central government to the local governments, there 37 items for general transfer payments, reaching 1243.442 billion RMB with a specific purpose, leading to $60 \%$ proportion of the funds that can't be integrated and used by the 
local governments. 1 In comparison with special transfer payments, the specific purposes for general transfer payments are more flexible and intensive. Even though such kind of general transfer payments is more flexible when compared with special payments, the ambiguous boundary between it with special transfer payments is easy to confuse the local governments, and solidify the used of the expenditure and lead to unnecessary funds precipitation.

\subsubsection{Special Transfer Payments}

The purpose of special transfer payments has been especially defined, so it shall be strictly monitored in its management and use, making sure a fixed sum is for a fixed purpose and there is no misappropriation. [9] It is because these features that leads to the following problems in the use of this fund among local governments:

First, The opacity of special transfer payments. Currently, there is no channel to get to know the specific sub-items, amount and use condition of special transfer payments, not to say the specific departments that approve these special transfer payments. Such opacity makes it more difficult to efficiently monitor transfer payments, and offer chances for the fund solidification of special transfer payments.

Second, incomplete exit mechanism of special transfer payments. In accordance with the "Measures for the administration of special transfer payments from central government to local governments" [10], the complete exit mechanism of special transfer payments shall be constructed and those that run contrary to the laws, regulations and relevant rules of the state council should be cancelled. The policy expiration, policy adjustment and objective conditions that have changed are unnecessary to carry out. The market competition mechanism is able to be efficiently regulated, and so on. However in practice, the complete exit mechanism has not been established, which makes it's hard to change the phenomenon of transfer payments solidification.

Third, the overlapping phenomenon of special transfer payments. Out of the multiple management, there will be information asymmetry about the use of funds for the payer of transfer payments, leading to the chaos of funds management and enhance the difficulty of integration.

\subsection{Unscientific and Unstandardized Budget Management Process Leads to Expenditure Solidification}

\subsubsection{Budget Preparation}

In practice, since the increasing unpredictable factors in international and domestic economic conditions, emphasis of social development and others, the accurate location of performance target, the delayed construction of the project bank and the efficient implementation of performance budget are affecting the process of reform. It is still difficult for Chinese governments at all levels to accurately compile budgets and the workload is large. At the same time, the compilation method of "base plus-increase" can better save

1 Data source: The state council's audit report on the implementation of the central budget and other fiscal revenues and expenditures in 2017. time, manpower and costs, this method is still used in budgeting. But this method is based on the original expenditure pattern and the expenditure in previous years is automatically extended to the new budget year. This gradual budgeting method result in the expenditure generally can only be increased and can't be reduced, and the lack of consideration for factors such as policy arrangement makes the expenditure pattern that has changed cannot be timely adjusted, thus curing the fiscal expenditure from its source.

\subsubsection{Budget Content}

In the process of practice, the different source of income, various expenditure goals and difference of policy limitation of "the four budget" lead to the unclear funds location in the bridging process and the efficient expenditure is hard to form. For example, the collection target and use range of the Government-managed Funds budget are specific, which is usually included to the relevant department and is the rights and power of the department. After transferring part of Government-managed Funds budget into the general public budget according to the rules of policy, the fiscal department cannot properly collect, distribute and use them in accordance with the income and expenditure pattern of the general public budget, resulting in the solidification of funds and the leading to difficulty of overall use.

\subsubsection{Budget Process}

Currently, the existing department budgetary compilation process in China involves "Two Top and Two Bottom" and it is carried out step by step. Specifically speaking, it includes submitting budget proposals as required by the superior department, issuing budget control limits after financial review, detailing the budget within the limits among departments and approving the departmental budget by the superior department. Since it is essential for the arrangement of budget funds to target department to smoothly compile the budget, the new "Budget law" has made specific requirement for the time nodes in the budgeting process. To be specific, it includes after the People's congresses at the corresponding levels approve the budget of each local governments, the financial department of the governments at the corresponding level shall approve the budget within 20 days, and so on.

However, under the process, there are many different department taking the management and overlapping functions, and thus the budget often exceeds the time limit when it finally reaches the use department, and there are even extreme phenomenon like the budget only be paid at the end of the year. Especially for funds with specific purpose, it cannot be normally used if the funds are not issued.

\subsection{The Contradiction Between Policy and System Arrangement and Practice Leads to the Unsmooth Use of Expenditure}

China as a country with a single system, the power of the lower level governments comes from the authorization of the higher level government. In theory, the higher government should formulate relevant policies from the overall 
perspective, and the lower government should fully implement them. However, since the long administrative radius of the higher government to the lower government departments, it is difficult to know the actual situation of the lower government or to guide and supervise them in real time. In addition, the policies formulated by the higher authorities are not necessarily applicable to the management of local specific matters. Moreover, as independent people, the officials in the local governments will selectively carry out the policies from the higher level according to their own interests, and thus the phenomenon of "government officials are neglectful of their duties" is produced. Thus, the contradiction between the arrangement of the superior system and the practical work is formed, and the solidification of the system leads to the solidification of expenditure.

\subsubsection{The Contradiction Between the Expenditure Progress Assessment and the Mode of Expenditure}

In order to revitalize the stock of financial funds and improve the utilization efficiency of financial funds, in 2014, the ministry of finance formulated the "Measures for assessing the progress of local budgetary expenditures" [11], which is stipulated Except social insurance fund budget, the expenditure progress of other three budgets need to be assessed. It is divided into monthly assessment and annual assessment, of which the monthly assessment involves four parts. It can be seen that in order to improve the efficiency of the use of fiscal funds, the central government has been strengthening the monitoring of the use of funds. But it has been found after survey and investigation that the quantification of such assessment indicators and the design of time nodes do not conform to the rules of actual operation, especially for the project funds, which can't be paid as a gradual way, but it is based on the requirements in the contract It can only be paid after the results are verified to meet a certain standard. Especially for large infrastructure projects, there are characteristics such as the construction period is too long and the project acceptance is difficult, which directly leads to the failure of the expenditure progress assessment.

\subsubsection{The Contradiction Between the Overall Budget Arrangement and Budget Composition}

According to the relevant regulations in the " The Budget Law of the PRC" and the "The circular of the ministry of finance on further strengthening the management of local financial balance and transfer funds" [12] and "Notice of the ministry of finance on further strengthening the implementation and management of the budget of fiscal expenditure" [13], the general public budget, government-managed funds budget, state capital operations budget and social insurance fund budget shall be closely related. Besides, it also include the specific coordination stipulations, such as if the amount of balance and transfer scale of the government-managed fund budget exceeds $30 \%$, it shall supplement the Budget stabilization fund. Funds that have not been used up for two consecutive years shall be used as balance of funds, and can be transferred to the general public budget then be used to supplement the Budget stabilization fund. Against the fiscal revenue is difficult to meet the rigid fiscal expenditure, these regulations undoubtedly alleviate the general public budget revenue and expenditure contradiction to a certain extent. But at the local level, different income structures will obstacle the optimization of such alleviation.

\subsubsection{The Contradiction Between the Medium-Term Rolling Budget and the Actual Compilation}

Based on the "Opinions of the State Council on the implementation of medium-term fiscal planning and management" [14], the financial department shall, together with other departments, formulate a three-year rolling financial plan and analyze and forecast the major fiscal revenues and expenditures in the next three years. In addition, the financial department shall also study policy objectives, operational mechanisms and evaluation measures for the major reforms, major policies and major projects in the planning period, and strengthen the binding force of fiscal planning on annual budgets by updating rolling management year by year. Generally speaking, all departments have prepared a rolling three-year budget according to relevant regulations. But through the survey, it was found that the subordinate departments did not know the working direction of the superior departments and the future projects they would carry out. In addition, there are some situations, such as too large budget changes, inaccurate budget reports from the unit, and temporary tasks from the superior, which make the preparation of the budget in the future years unscientific. In particular, project funds of engineering are greatly affected by their own discontinuity and policy changes. In this context, the preparation of a three-year rolling budget is more likely to be superficial and unpractical, but the arrangement of the amount of fiscal expenditure was settled unscientifically in advance, leading to the formation of funds solidification.

\section{Policy Suggestion}

It can conclude from the above analysis that at present, there are some reasons such as unreasonable system design, unconformity of policy requirements and unscientific management methods in China, the financial funds are in a rigid and rigid state [15]. Therefore, we should start from the top-level design, improving the supporting measures and strengthening the modern budget management.

\subsection{Completing the Supporting Measures}

First and foremost, in terms of legally mandated mechanism, the relevant laws, regulations and policy documents that still have relevant requirements should be cleaned up, and supporting policy documents or laws should be further issued, so that the costs for increasing such expenditures will be increased. For projects that coincide with key livelihood projects, arrangements are made according to local conditions based on preliminary feasibility analysis, truly ensuring the development of projects aimed at improving people's wellbeing. 
Second, as for special transfer payments, it shall first fully consider the mutual influence of different types of transfer payments. The transfer payments model shall be chosen according to the regional economic situation, structure and other factors. Then, the provisions that "special transfer payments arranged by the higher government shall not require the lower government to undertake supporting funds" shall be strictly followed. The existing policies involving special projects shall be comprehensively sorted out, and it shall be supplemented in accordance with the classification standard of transfer payments and the principle of subsidy, speeding up the use of funds after the release of progress. At last, in the process of improving the transfer payments system, the responsibility of providing public goods or services should be defined more clearly, completing the mechanism for withdrawing special transfer payments.

\subsection{Comprehensively Implement Budget Performance Management}

China can build "a comprehensive, whole-process and extensive budget performance management system". First of all, the comprehensive budget performance management shall be expanded to all kinds of budget, namely promoting it from the general budget project expenditure performance management to budget department overall expenditure, fiscal revenue and expenditure policy. On the basis of continuing to explore the system of transfer payments, it shall gradually expand to the financial operation of governments at all levels. Through the establishment and improvement of government budget performance management, departmental budget performance management, policy and project budget performance management, we can finally achieve a comprehensive performance management pattern. Then, to realize the whole process of budget management. The synchronous management of the budget preparation, implementation, supervision and other processes with the performance management can ensure the whole process of financial capital acceptance performance management. Finally, to achieve full budget coverage. Including all financial resources in performance management, namely, expanding from the general public budget to government-managed funds budget, state capital operations budget and social insurance fund budget, supervising all financial capital projects, budget units and budget departments, making sure the match between "expenditure money" and " practically doing things", and preventing the phenomenon of "finding project with money" and reducing the possibility of the funds cannot be efficiently paid.

\subsection{Determine a Reasonable Amount of Spending}

First, the government should further clarified the scope of public financial support, then determine the boundary between government, market and society, and withdraw from areas that should not be interfered, and give full play to market competitiveness. Through the transformation of government functions, clarifying the responsibilities of government departments, solving the problem of fragmentation, and the realization of comparative advantage to form the scale of resultant expenditure.

Second, to establish the activity mechanism of horizontal and vertical clear management level, from the function of management organization adjustment, government should change the management mechanism on interweave mesh structure, make the cash flow in the direction of the horizontal and vertical emphasis, reduce overlap and duplication in the use of funds, in the backdrop of the rigid spending to reduce waste of money.

Thirdly, government should establish a reasonable budget preparation method based on the modern budget system to determine the scientific expenditure scale, and promote the zero-base budget in real earnest, and give full consideration to the realistic difficulties in the future planning of development direction to determine the expenditure scale.

\subsection{Reasonable Arrangement of Dispensing Rights}

In the first place, in terms of the distribution of fund allocation right among different stakeholders, the fund allocation right of government budget departments can be gradually reduced, correspondingly expanding the rights of users of funds and legislative oversight bodies. In this way, with the full use of the information advantage of the department using the funds, the use of funds supervision is strengthened. Secondly, in terms of the specific operation of budget funds, when the overall requirements are met, greater flexibility shall be given to department using the funds. [16] This means that under the total scale of budget expenditure, the department using the budget may independently arrange the amount of expenditure for various purposes according to the work priorities of this year.

\section{References}

[1] Ministry of Finance. Guidance on further budget implementation [Z]. 2010-01-22.

[2] Ministry of Finance. Notification of measures to assess the progress of local budgetary expenditures [Z]. 2014-07-23.

[3] Ministry of Finance. Notice on strengthening the management of local budget implementation and accelerating the progress of expenditure [Z]. 2018-05-03.

[4] Shushen Liu. The Scientificity and Soft Constraints of Government Budget - An Empirical Analysis Based on the Implementation of China's Fiscal Budget [J]. Chinese Public Administration, 2010 (2): 110-115.

[5] Guohai Duan. Measures to Break Solidification of Fiscal Spending [J]. Budget Management \& Accounting, 2017 (6):45-48

[6] Chuang Cai. The Analysis of the Historical Evolution and Cause of the Solidification of Fiscal Expenditure Structure Based on the Perspective of National Governance and Fiscal Risk [J]. Journal of Hunan Taxation College, 2017 (4):21-27. 
[7] Research group of China academy of fiscal sciences. Risks of Solidifying Fiscal Expenditure [J]. New Finance (government finance), 2017 (3): 83-86.

[8] Xiaolan Deng, et al. Research on Fiscal Sustainability's Problems and Solutions under the New Normal: Also Focus on Fiscal Supply-Side Reform Policy [J]. Journal of Central University of Finance \& Economics, 2017 (1):20-27.

[9] Kegu Liu. China's fiscal and taxation reform has been in the past 30 years [M]. Beijing: Economic Science Press, 2008.

[10] Ministry of Finance. Measures for the administration of special transfer payments from central government to local governments [Z]. 2015-12-30.

[11] Ministry of Finance. Measures for assessing the progress of local budgetary expenditures [Z]. 2014.
[12] Ministry of Finance. The circular of the ministry of finance on further strengthening the management of local financial balance and transfer funds [Z]. 2013-10-21.

[13] Ministry of Finance. Notice of the ministry of finance on further strengthening the implementation and management of the budget of fiscal expenditure [Z]. 2014-5-21.

[14] NDRC. Opinions of the State Council on the implementation of medium-term fiscal planning and management [Z]. 2015-01-23.

[15] Guang Yang, et al. The Solidified Structure of Fiscal Expenditure: Reform is Imminent [N]. China Economic News, 2017-02-28.

[16] Qingwang Guo, et al. Fiscal Decentralization, Government Structure and Local Government's Expenditure Size [J]. Economic Research Journal, 2010 (11):59-72. 